\title{
Chitosan Hydrophobic Domains are Favoured at Low Degree of Acetylation and Molecular Weight
}

\author{
Ramon Novoa-Carballal, Ricardo Riguera,* and Eduardo Fernandez-Megia* \\ Department of Organic Chemistry and Center for Research in Biological Chemistry and Molecular Materials (CIQUS), University of \\ ${ }_{5}$ Santiago de Compostela, Jenaro de la Fuente s/n, 15782 Santiago de Compostela, Spain.
}

E-mail: ricardo.riguera@usc.es (R.R.); ef.megia@usc.es (E.F.-M.).

\begin{abstract}
The aggregation of chitosan (CS) has been studied as a function of concentration, degree of acetylation (DA), and degree of polymerization (DP) by means of pyrene fluorescence and rheology. ${ }_{10}$ Fluorescence experiments show that aggregation of CS involves hydrophobic domains (HD) which are more favoured as lower the DA and DP. Consistent with these results, the viscosity of CS solutions decreases continuously on increasing DA, in the whole range of DP. These results, which rule out the participation of the acetyl groups in the HD, have been interpreted by the theory of hydrophobic polyelectrolytes in terms of the electrostatic energy of the aggregates.
\end{abstract}

15 Keywords: chitosan, aggregation, pyrene fluorescence, rheology, SEC-MALLS

\section{Introduction}

Chitosan (CS, Figure 1) is a linear cationic polysaccharide obtained by $N$-deacetylation of chitin, a structural component of crustacean shells and fungal cell walls that is commercially

20 obtained at low cost from seafood processing. CS is composed of variable proportions of $\beta(1-4)$ linked glucosamine and $N$ acetylglucosamine. ${ }^{1}$ Thanks to its low toxicity, and high biodegradability, biocompatibility, and mucoadhesion, CS has emerged as an interesting biopolymer in drug delivery, ${ }^{2,3}$ tissue ${ }_{25}$ engineering, ${ }^{4,5}$ biofabrication, ${ }^{6}$ and the food industry. ${ }^{7,8}$ The applications of CS mostly depend on its tendency to aggregate in solution, a process controlled by external $(\mathrm{pH}$, ionic strength, temperature) and structural [degree of acetylation (DA), degree of polymerization (DP)] parameters. As a result, much effort has 30 been devoted to study the aggregation of CS by different techniques. Rheological studies have shown that the semidilute regime in CS starts at $c a .1 \mathrm{~g} / \mathrm{L}\left(\mathrm{C}^{*}\right.$, depending on DA and DP). At higher concentrations, CS chains start entangling (5-13 g/L, $\mathrm{C}^{* *}$ ) to finally form gels at $c a .45 \mathrm{~g} / \mathrm{L} .{ }^{9,10}$ Liquid crystal 35 properties for $\mathrm{CS}$ have been also observed by polarizing microscopy in more concentrated solutions..$^{11,12}$

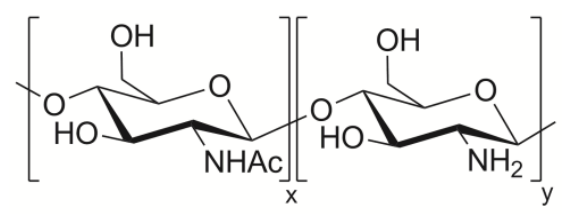

Fig. 1. Chitosan (CS).
40 The presence of aggregates in solutions of CS has been reported by static light scattering (SLS) $)^{13,14}$ and dynamic light scattering (DLS). ${ }^{15,16,17,18,19}$ In a recent contribution, Boucard and co-workers have analysed a series of CS samples by small-angle synchrotron X-ray scattering (SAXS) in the semidilute regime. ${ }^{20}$ ${ }_{45}$ In this study, the upturn at low angle range demonstrates that the solutions are heterogeneous and consist of well dissolved polymer chains that coexist with aggregated domains. In addition, the position of the maximum of the polyelectrolyte scattering peak scaled with the polymer concentration as predicted by the 50 theory of hydrophobic polyelectrolytes developed by Dobrynin and Rubinstein ${ }^{21,22,23}$ pointing to a pearl-necklace conformation for CS in solution. Nevertheless, neither the driving force for these ordered structures in solution nor the role of DA and DP on the aggregation of CS are fully understood yet. Thus, while some ${ }_{55}$ SLS experiments have shown an increased aggregation of CS with DA (interpreted as resulting from the formation of hydrophobic interactions between $N$-acetyl groups), ${ }^{13}$ more recent DLS studies have resulted in no differences in aggregation with DA. ${ }^{17}$ Several research groups have also observed the presence of 60 hydrophobic domains (HD) in solutions of CS by means of fluorescence experiments using pyrene as a polarity probe. Unfortunately, samples with very close DA values were analysed, whereas the influence of DP on aggregation has been a subject of discrepancy. ${ }^{24,25,26,27}$ In a more recent contribution it has been ${ }_{65}$ described the use of pyrene fluorescence with a series of CS samples having similar DP and varying DA (0-56). These experiments did not show a linear dependence of aggregation with DA, but revealed aggregation for samples with DA 0 , 
indicating that interactions between $N$-acetyl groups might not be the main reason for aggregation. ${ }^{28}$ Hydrogen bonds between CS chains which are known in the crystal structure ${ }^{29}$ have been also claimed to participate in the aggregation of the polymer in 5 solution. ${ }^{24,25}$

In this context, to further develop the applications of CS as a biocompatible polymer, there is an urgent necessity of additional studies to unravel the interactions operating in solutions of CS at a molecular level as a function of DP and DA. In a recent 10 contribution from our laboratory, we have reported a ${ }^{1} \mathrm{H}$ NMR relaxation study on the dynamics of CS (DA 1-70, DP 10-1200) in solution as a function of the temperature, concentration, and ionic strength. ${ }^{30}$ This analysis pointed to $\mathrm{CS}$ as a semi-rigid polymer with increased flexibility at higher DA, in agreement

15 with a reduced electrostatic repulsion between protonated amino groups. As a step further in our efforts to ascertain the behaviour of CS in solution and its applications in drug delivery, ${ }^{31,32,33}$ herein we report a detailed study of the aggregation of CS with different DP (360-1200) and DA (0-70) by means of pyrene

20 fluorescence, rheology, and size exclusion chromatographymultiangle laser light scattering (SEC-MALLS). Notably, our results indicate the aggregation of $\mathrm{CS}$ involves $\mathrm{HD}$ which are more favoured at lower DA and DP. ${ }^{34}$

\section{Experimental}

25 Three commercial CS samples with different DP and DA were purchased and denoted as $\mathrm{C}_{\mathrm{x}-\mathrm{y}}$, where $\mathrm{x}$ represents the DP, and $\mathrm{y}$ the DA. Sample $\mathrm{CS}_{360-7}$ was obtained from FMC BioPolymer as hydrochloride salt: Protasan $\mathrm{Cl} 110$ (batch number 310-490-01). Samples $\mathrm{CS}_{730-17}$ and $\mathrm{CS}_{1200-20}$ were obtained from 30 Fluka: CS low MW (catalog number 22741, lot 407568/1) and CS high MW (catalog number 22743, lot 371936/1), respectively. These commercial samples were dissolved in $0.5 \%(\mathrm{w} / \mathrm{v}) \mathrm{AcOH}$ and purified by sequential dialysis against $10^{-3} \mathrm{M} \mathrm{HCl}, 5.5 \times 10^{-3}$ $\mathrm{M} \mathrm{NH} \mathrm{N}_{4} \mathrm{OH}$, and deionized water. After lyophilization, CS 35 samples were obtained in their deprotonated form.

DA values were determined in $2 \% \mathrm{DCl}$ at $298 \mathrm{~K}$, or in $20 \%$ $\mathrm{DCl}$ at $343 \mathrm{~K}$ for samples with DA over $40 .{ }^{35,36}$ Determination of the GINAc distribution in commercial samples was carried out by analysis of the relative intensities of the dyad frequencies in ${ }^{13} \mathrm{C}$ ${ }_{40} \mathrm{NMR},{ }^{37}$ using modified acquisition parameters (62.9 $\mathrm{MHz}$, 200.000 scans, $0.1 \mathrm{~s}$ acquisition time, no relaxation delay). With this aim, commercial CS samples were dissolved in $0.16 \mathrm{M}$ TFA$d$ (deuterated trifluoroacetic acid) $(30 \mathrm{~g} / \mathrm{L})$ and treated with $1 \mathrm{M}$ $\mathrm{NaNO}_{2}$ to reduce the DP. The analysis showed a homogeneous 45 distribution of $\mathrm{N}$-acetylglucosamine units along the polymer chains.

N-Deacetylation of CS. Finely grounded CS samples were suspended with stirring in an aqueous $40 \% \mathrm{NaOH}$ solution at 333-353 K, under a $\mathrm{N}_{2}$ stream. After $15-45 \mathrm{~min}$, the reaction 50 mixture was filtered, washed thoroughly with warm deionized water $(333 \mathrm{~K})$, and dried overnight under vacuum $\left(\mathrm{P}_{2} \mathrm{O}_{5}\right)$. The process was repeated until the desired DA was obtained. ${ }^{38}$

$\mathrm{N}$-Acetylation of CS. CS samples were homogenously $\mathrm{N}$ acetylated following known procedures. ${ }^{39}$ Briefly, CS samples 55 were dissolved $(10 \mathrm{~g} / \mathrm{L})$ in a $1: 1$ mixture $0.5 \%(\mathrm{w} / \mathrm{v}) \mathrm{AcOH} / 1,2-$ propanediol at $\mathrm{rt}$. Then, in order to reach a certain DA value, a freshly prepared solution of $\mathrm{Ac}_{2} \mathrm{O}$ in 1,2-propanediol was added.
The resulting solution was stirred at $\mathrm{rt}$ for $2 \mathrm{~h}$. After sequential dialysis against $10^{-3} \mathrm{M} \mathrm{HCl}, 5.5 \times 10^{-3} \mathrm{M} \mathrm{NH}_{4} \mathrm{OH}$, and deionized 60 water, the $\mathrm{CS}$ solution was lyophilized.

Fluorescence experiments. $10^{-6} \mathrm{M}$ pyrene solutions in aqueous $0.056 \mathrm{M}$ TFA or $0.2 \mathrm{M} \mathrm{AcOH} / 0.15 \mathrm{M} \mathrm{NH}_{4} \mathrm{OAc}$ buffer (pH 4.5) were prepared as follows: $200 \mu \mathrm{L}$ of a $2 \times 10^{-2} \mathrm{M}$ pyrene solution in $\mathrm{CH}_{2} \mathrm{Cl}_{2}$ were added to a $5 \mathrm{~L}$ round bottom flask ${ }_{65}$ followed by $200 \mathrm{~mL}$ of $\mathrm{CH}_{2} \mathrm{Cl}_{2}$. After mixing, the solvent was evaporated and the flask submitted to high vacuum for $1 \mathrm{~h}$. Then, $4 \mathrm{~L}$ of $0.056 \mathrm{M}$ TFA or $0.2 \mathrm{M} \mathrm{AcOH} / 0.15 \mathrm{M} \mathrm{NH} 4 \mathrm{OAc}$ were added. After $72 \mathrm{~h}$ of stirring, solutions were filtered through a $0.45 \mu \mathrm{m}$ pore size membrane. These aqueous solutions of pyrene 70 were then used to dissolve CS at a concentration 8-11 g/L. These solutions were subsequently diluted stepwise down to $10^{-4} \mathrm{~g} / \mathrm{L}$ (before each dilution step, samples were stirred for at least $8 \mathrm{~h}$ ). Fluorescence experiments were performed on a Spex Fluoromax spectrometer. Emission spectra of pyrene were obtained by 75 exciting samples at $333 \mathrm{~nm}$ and measuring the emission between $340-550 \mathrm{~nm}$. The slit width was adjusted to $5 \mathrm{~nm}$ for the excitation and $1.5 \mathrm{~nm}$ for the emission with an integration time of $1 \mathrm{~s} / \mathrm{nm}$.

Rheology. The rheological behavior of the CS samples was 80 determined in a rheometer (Rheolyst AR1000N, TA Instruments, New Castle, DE, USA) equipped with a data analyzer AR2500 and a Peltier plate, a cone-plate geometry with a diameter of 60 $\mathrm{mm}, 2.1^{\circ}$ and a $59 \mu \mathrm{m}$ gap to the Peltier plate. The shear viscosity was measured between 0.1 and $100 \mathrm{~s}^{-1}$. The response to an 85 oscillatory shear stress ( $\mathrm{G}^{\prime}$ and $\mathrm{G}^{\prime \prime}$, storage and loss moduli) was determined by applying an oscillatory shear force of $0.1 \mathrm{~Pa}$ and an angular frequency sweep between 0.05 and $50 \mathrm{rad} \cdot \mathrm{s}-1$. CS samples were dissolved in $0.056 \mathrm{M}$ TFA, $24 \mathrm{~h}$ or 12 days before measurements. In addition, samples $\mathrm{CS}_{1200-3}$ and $\mathrm{CS}_{1200-70}$ were 90 also analysed 12 days after being dissolved.

SEC-MALLS. An Iso Pump G1310A (Hewlett Packard) was connected to two PSS Novema GPC columns $(10 \mu \mathrm{m}, 30 \AA$, $8 \times 300 \mathrm{~mm}$; and $10 \mu \mathrm{m}, 3000 \AA, 8 \times 300 \mathrm{~mm})$. A PSS SLD7000 MALLS detector (Brookhaven Instruments Corporation) 95 operating at $660 \mathrm{~nm}$ and a G1362A refractive index detector (Agilent) were connected on line. A $0.15 \mathrm{M} \mathrm{NH}_{4} \mathrm{OAc} / 0.2 \mathrm{M}$ $\mathrm{AcOH}$ buffer $(\mathrm{pH}=4.5)$ was used as eluent. Polymer solutions were filtered through $0.2 \mu \mathrm{m}$ pore size membranes before injection. Polymer concentrations were in the range 0.1 to $5 \mathrm{~g} / \mathrm{L}$ 100 depending on DP and DA. Refractive index increments $\mathrm{dn} / \mathrm{dC}$ were taken from the literature. ${ }^{40,41,42}$

\section{Results and discussion}

A set of $19 \mathrm{CS}$ samples covering 3 different DP $(360,730$, 1200) and DA values 0-70 were prepared from 3 commercial 105 samples, namely $\mathrm{CS}_{360-7}, \mathrm{CS}_{730-17}$, and $\mathrm{CS}_{1200-20}$, and characterized by size exclusion chromatography-multiangle laser light scattering (SEC-MALLS) (Table 1). The analysis of the relative intensities of the dyads in the ${ }^{13} \mathrm{C}$ NMR spectra of these commercial samples assures a homogeneous distribution of $\mathrm{N}$ 110 acetylglucosamine units along the polymer chain. ${ }^{37}$ From these samples, CS with varying DA were obtained by $N$-acetylation ${ }^{39}$ and $N$-deacetylation, ${ }^{38}$ following procedures ensuring a homogeneous distribution of $N$-acetyl groups. 
Table 1. Structural parameters of the CS samples studied.

\begin{tabular}{ccccc}
\hline $\mathbf{C S}^{a}$ & $\begin{array}{c}\boldsymbol{M}_{\mathbf{w}}{ }^{\boldsymbol{b}} \mathbf{( 1 0}^{\mathbf{5}} \\
\mathbf{g} / \mathbf{m o l})\end{array}$ & $\mathbf{D P}^{{ }{ }^{b}}$ & $\mathbf{D A}^{\boldsymbol{c}}$ & $\mathbf{P D I}^{b}$ \\
\hline & & & & \\
$\mathrm{C}_{360-1}$ & 0.58 & 359 & 1 & 1.45 \\
$\mathrm{C}_{360-7}$ & 0.57 & 343 & 7 & 1.61 \\
$\mathrm{C}_{360-19}$ & 0.67 & 365 & 19 & 1.38 \\
$\mathrm{C}_{360-30}$ & 0.63 & 365 & 30 & 1.50 \\
$\mathrm{C}_{360-39}$ & 0.63 & 355 & 39 & 1.35 \\
$\mathrm{C}_{360-48}$ & 0.69 & 369 & 48 & 1.55 \\
$\mathrm{C}_{360-70}$ & 0.70 & 369 & 70 & 1.70 \\
$\mathrm{C}_{730-0}$ & 1.23 & 762 & 0.2 & 1.43 \\
$\mathrm{C}_{730-6}$ & 1.26 & 769 & 6 & 1.23 \\
$\mathrm{C}_{730-17}$ & 1.21 & 719 & 17 & 1.42 \\
$\mathrm{C}_{730-27}$ & 1.35 & 782 & 27 & 1.31 \\
$\mathrm{C}_{730-39}$ & 1.28 & 721 & 39 & 1.24 \\
$\mathrm{C}_{730-70}$ & 1.32 & 700 & 70 & 1.12 \\
$\mathrm{C}_{1200-1}$ & 1.89 & 1170 & 1 & 1.20 \\
$\mathrm{C}_{1200-3}$ & 1.89 & 1163 & 3 & 1.40 \\
$\mathrm{C}_{1200-20}$ & 2.06 & 1214 & 20 & 1.51 \\
$\mathrm{C}_{1200-40}$ & 2.17 & 1219 & 40 & 1.37 \\
$\mathrm{C}_{1200-50}$ & 2.35 & 1238 & 50 & 1.60 \\
$\mathrm{C}_{1200-70}$ & 2.28 & 1200 & 70 & 2.00 \\
${ }^{a}{ }^{a}$ Commercial samples: $\mathrm{C}_{360-7}, \mathrm{C}_{730-17}$, and $\mathrm{C}_{1200-20 .}{ }^{b}$ Determined by SEC- \\
MALLS. $^{c}$ Determined by ${ }^{1} \mathrm{H}$ NMR.
\end{tabular}

Pyrene fluorescence. As mentioned in the introduction, the 10 presence of HD in solutions of CS has been studied in the past by fluorescence using pyrene as a hydrophobic probe. ${ }^{24-28}$ From these studies, however, no clear dependence of aggregation on DA and DP has resulted. With the purpose of shedding light on this relevant property of CS, we have recorded steady state 15 emission spectra of a whole set of CS samples with different DA and DP (CS $360-1, \mathrm{CS}_{360-19}, \mathrm{CS}_{360-39}, \mathrm{CS}_{360-70}, \mathrm{CS}_{730-0}, \mathrm{CS}_{730-6}$, $\mathrm{CS}_{730-17}, \mathrm{CS}_{730-70}, \mathrm{CS}_{1200-1}, \mathrm{CS}_{1200-20}, \mathrm{CS}_{1200-70}$ ), dissolved at different concentrations in $0.056 \mathrm{M}$ TFA using a fixed $10^{-6} \mathrm{M}$ concentration of pyrene.

20 A quick look at the spectra in Figure $2\left(\mathrm{CS}_{360-1}, \mathrm{CS}_{360-70}\right)$ and Figure $\mathrm{S} 1\left(\mathrm{CS}_{730-0}, \mathrm{CS}_{730-70}, \mathrm{CS}_{1200-1}, \mathrm{CS}_{1200-70}\right)$ reveals drastic variations in the emission of pyrene when the concentration of CS is increased irrespective of DP and DA, in agreement with the appearance of HD. Interestingly, as concentration increases all 25 samples display broad characteristic peaks corresponding to pyrene excimers. This excimer is blue shifted $(420 \mathrm{~nm})$ in all samples with the exception of $\mathrm{CS}_{360-70}(470 \mathrm{~nm})$. This blue shifted excimer of high energy is typically observed in molecular assemblies ${ }^{43}$ and implies the presence of two pyrene molecules in 30 close proximity during excitation. ${ }^{44}$
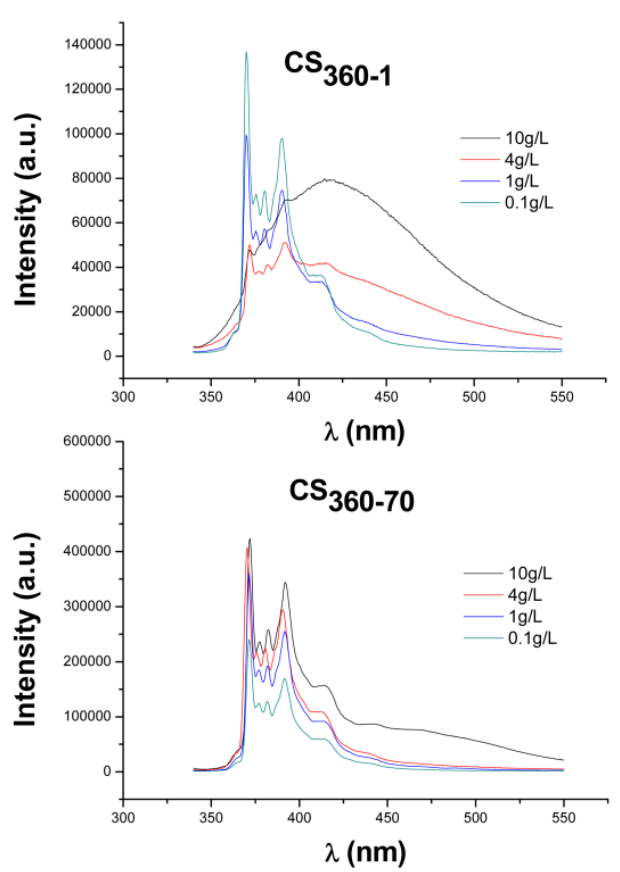

Fig. 2. Steady state fluorescence emission spectra of pyrene in solutions of $\mathrm{CS}_{360-1}$ and $\mathrm{CS}_{360-70}\left(0.056 \mathrm{M}\right.$ TFA, $298 \mathrm{~K}, 10^{-6} \mathrm{M}$ pyrene, excitation at 35 $333 \mathrm{~nm})$.

Important information on the aggregation of CS can be extracted by analyzing the $\mathrm{I}_{\mathrm{E}} / \mathrm{I}_{\mathrm{M}}$ relative intensity of the excimer (IE) and monomer $\left(\mathrm{IM}_{\mathrm{M}}, 372 \mathrm{~nm}\right)$, which is proportional to the concentration of unexcited pyrene molecules in the neighborhood 40 of excited probes, and so relates to the concentration of HD. ${ }^{45}$ The intensity of the excimer is expected to depend on the relative concentration between pyrene and HD. Thus, in the experiments herein reported, the steady increase of $\mathrm{I}_{\mathrm{E}} / \mathrm{I}_{\mathrm{M}}$ with the concentration of CS (Figure 3) points to a concomitant increased 45 concentration of $\mathrm{HD}$, which anyway remains below $10^{-6} \mathrm{M}$ (the concentration of pyrene probes). The only exception to this general behavior is $\mathrm{CS}_{360-1}$, where a reduction of $\mathrm{I}_{\mathrm{E}} / \mathrm{I}_{\mathrm{M}}$ was observed between 8 and $10 \mathrm{~g} / \mathrm{L}\left(\mathrm{ca} .5 \times 10^{-2}\right.$ and $6 \times 10^{-2} \mathrm{M}$ of monomers, respectively) in agreement with the concentration of ${ }_{50} \mathrm{HD}$ exceeding in this case $10^{-6} \mathrm{M}$ (reduced probability for two pyrene molecules to coexist inside a single HD). This behavior is coherent with this sample displaying the highest tendency to form HD among those in Table 1.

The relative intensity of the first $\left(\mathrm{I}_{1}, 372 \mathrm{~nm}\right)$ and third $\left(\mathrm{I}_{3}\right.$, ${ }_{55} 382 \mathrm{~nm}$ ) vibronic bands in the fluorescence spectrum of pyrene $\left(I_{1} / I_{3}\right)$ reports the polarity of the environment: higher $I_{1} / I_{3}$ values in polar environments. ${ }^{46}$ As seen in Figure $3, \mathrm{I}_{1} / \mathrm{I}_{3}$ shows constant values around 1.9 at monomer concentrations lower than $c a$. $5 \times 10^{-3} \mathrm{M}$ (equivalent to $c a$. $1 \mathrm{~g} / \mathrm{L}$ ). This value is coincident with 60 that for pyrene in $0.056 \mathrm{M}$ TFA which is indicative of the absence of HD. At higher concentrations of CS, nevertheless, a sharp decrease in $\mathrm{I}_{1} / \mathrm{I}_{3}$ was accompanied by an increase in $\mathrm{I}_{\mathrm{E}} / \mathrm{I}_{\mathrm{M}}$ independently on DA and DP, which reflects the formation of HD. 

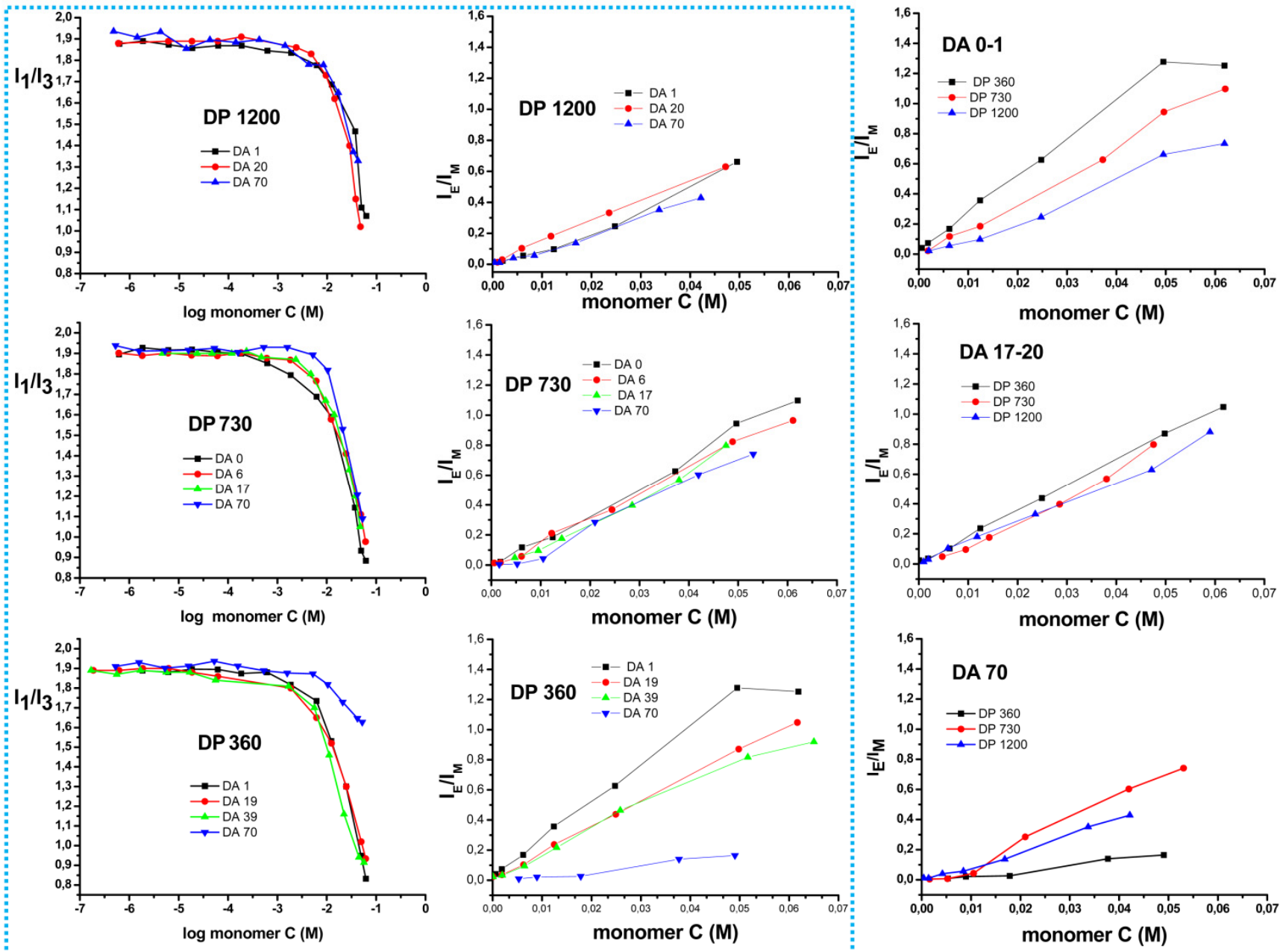

Fig. 3. Variation of $I_{1} / I_{3}$ (left) and $I_{E} / I_{M}$ (centre) with the molar concentration of CS monomers in 0.056 M TFA as a function of DA. Right column represents the variation of $\mathrm{I}_{\mathrm{E}} / \mathrm{I}_{\mathrm{M}}$ with the molar concentration of monomers as a function of DP.

A closer analysis of the variation of $\mathrm{I}_{1} / \mathrm{I}_{3}$ and $\mathrm{I}_{\mathrm{E}} / \mathrm{I}_{\mathrm{M}}$ with $\mathrm{DA}$ 5 and DP shows relevant information on the aggregation of CS. As shown in Figure 3, as the concentration of CS increases, lower $\mathrm{I}_{1} / \mathrm{I}_{3}$ values associated to the onset of HD were firstly observed for the less acetylated samples, a trend that revealed more pronounced at lower DP. Similarly, the aforementioned increase 10 of $\mathrm{I}_{\mathrm{E}} / \mathrm{I}_{\mathrm{M}}$ with concentration was more marked at lower DA, and this phenomenon again more important as lower the molecular weight.

In the above fluorescence experiments performed in TFA, the $\mathrm{pH}$ of the solutions under study is slightly influenced by the DA 15 and concentration of the samples. For instance, $\mathrm{pH} 1.2$ for the mother $0.056 \mathrm{M}$ TFA solution increases up to 1.7 when dissolving samples of $\mathrm{DA} \sim 0$ at $8 \mathrm{~g} / \mathrm{L}\left(c a .5 \times 10^{-2} \mathrm{M}\right.$ of monomers). With the intention of ruling out any undesired bias of $\mathrm{pH}$ on the formation of $\mathrm{HD}$, pyrene fluorescence experiments 20 were also performed with representative $\mathrm{CS}$ samples $\left(\mathrm{CS}_{360-1}\right.$,
$\mathrm{CS}_{360-70}, \mathrm{CS}_{1200-1}, \mathrm{CS}_{1200-70}$ ) in a $0.15 \mathrm{M} \mathrm{NH}_{4} \mathrm{OAc} / 0.2 \mathrm{M} \mathrm{AcOH}$ buffer solution at $\mathrm{pH} 4.5$ (Figure S2). Interestingly, these experiments afforded similar results as those observed in TFA in agreement with the complete protonation of CS under these 25 experimental conditions. . $^{47,48}$

Overall, these observations indicate an increased tendency of the less acetylated CS samples to participate in HD, an effect also observed for the lower DP samples with the only exception of

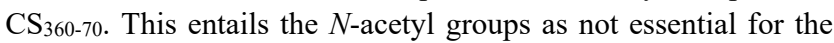
30 formation of HD. Similar outcome has been recently pointed out by the group of Philippova (in regard to DA, not to DP), ${ }^{28}$ although in this case a non-linear dependence between $\mathrm{I}_{1} / \mathrm{I}_{3}$ and DA complicated interpretation. Our data show that irrespective of DA and DP, $\mathrm{I}_{1} / \mathrm{I}_{3}$ and $\mathrm{I}_{\mathrm{E}} / \mathrm{I}_{\mathrm{M}}$ start varying at concentrations around ${ }_{35} 1 \mathrm{~g} / \mathrm{L}$ ( $c a .5 \times 10^{-3} \mathrm{M}$ of monomers), a value close to the overlap concentration $\left(\mathrm{C}^{*}\right)$, which is an indication of the intermolecular nature of the HD probed by pyrene. The higher tendency of low 
DA samples to participate in HD agrees well with the increased stiffness and higher intrinsic viscosity of these samples. ${ }^{30,49}$ As for the variation of $\mathrm{I}_{1} / \mathrm{I}_{3}$ and $\mathrm{I}_{\mathrm{E}} / \mathrm{I}_{\mathrm{M}}$ with $\mathrm{DP}$, it was surprising to see the higher tendency of the CS samples with lower DP to 5 participate in $\mathrm{HD}$ (with the exception of $\mathrm{CS}_{360-70}$ ). This interesting result indicates that the formation of HD might be preferentially occurring at the chain ends (lower DP entail higher concentrations of chain ends).

10 The polyelectrolyte character of CS. With the aim of rationalizing these results, we turned our attention to the theory of hydrophobic polyelectrolytes developed by Dobrynin and Rubinstein. ${ }^{21-23}$ A recent study by SAXS has proposed CS in the semidilute regime as following a pearl-necklace model that ${ }_{15}$ agrees with this theory. ${ }^{20}$ According to Dobrynin and Rubinstein, hydrophobic polyelectrolytes can be modeled as a sequence of $\mathrm{N}$ monomers of size $b$, from which a known fraction $(f)$ is charged. This model allows, with the help of classical physics, to understand the chain conformation of hydrophobic 20 polyelectrolytes at different concentration ranges, and to predict the scaling behavior of some measurable properties. The conformation of hydrophobic polyelectrolytes in water is determined by the interplay between electrostatic and hydrophobic interactions. Thus, while in the dilute regimen a 25 neutral polymer in a bad solvent is expected to form spherical globules to minimize the polymer-solvent interaction, in a hydrophobic polyelectrolyte above a certain $f$ value, the globule splits in a sequence of smaller globular structures (beads) that are interconnected by strings (pearl-necklace conformation) to reduce 30 the electrostatic energy of the system. At concentrations above $\mathrm{C}^{*}$, this succession of globules is also adopted at distances shorter than the correlation length $\xi$, while for length scales greater than $\xi$, the chain is governed by Gaussian statistics.

According to this theory, the electrostatic energy for 35 aggregates in $\mathrm{CS}$ can be expressed by the Equation 1 developed by Dobrynin:

$$
\frac{\text { Uelect }}{k T} \approx \frac{l_{B} f^{2} g_{\xi}^{2}}{\xi} \approx \frac{\tau^{5 / 4}}{\left(u f^{2}\right)^{1 / 4}}\left(c_{p} b^{3}\right)^{-1 / 2}
$$

where $l_{B}$ is the Bjerrum length, $f$ the fraction of charged monomers (1-DA/100), $g_{\xi}$ is the number of monomers inside the $40 \xi, \tau$ is the effective temperature $[\tau=1-\Theta / \mathrm{T}$, where $\Theta$ is the theta temperature)], $c_{p}$ is the polymer concentration, $b$ is the monomer length, and $u$ is the interaction parameter $\left[u=(1-\mathrm{DA} / 100) l_{B} / b\right]$. In accordance with this equation, aggregates between chains involving a reduced electrostatic energy will be favored.

$45 \quad$ Figure 4 depicts a schematic representation of end to end and side by side aggregation modes for CS chains of similar DA. In line with Eq. 1, the formation of end to end aggregates results in a reduced electrostatic energy compared to a side by side mode because of the smaller number of monomers and charges 50 involved within $\xi$; a result that agrees with our fluorescence experiments and the higher tendency of low DP samples to participate in HD.
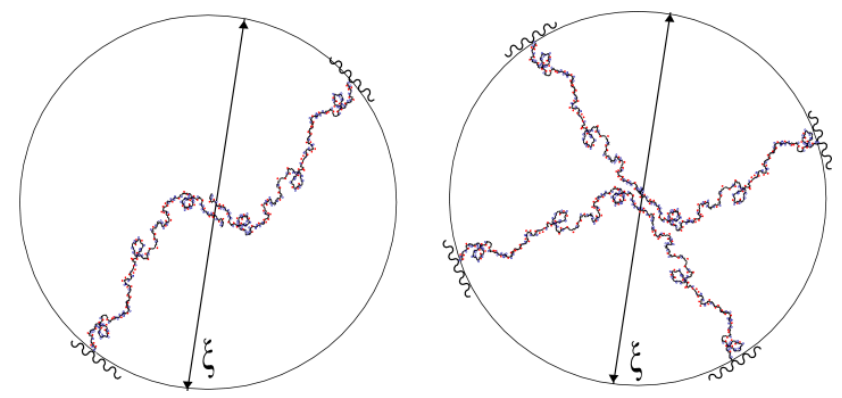

Fig. 4. Schematic representation of end to end (left) and side by side 55 (right) aggregation modes for CS. Charges are represented by red points and acetyl groups by blue points.

Another interesting outcome from Eq.1 results of comparing the aggregation of CS with different DA. As schematically represented in Figure 5, the higher monomer concentration inside ${ }_{60} \xi$ for the more flexible highly acetylated samples ${ }^{30}$ compensates their lower charge density, to render an increased electrostatic energy in the aggregates. This effect along with the lower intrinsic viscosity of highly acetylated CS explains the reduced concentration of HD experimentally observed for these samples.

65 An exception to the above aggregation trends is seen in $\mathrm{CS}_{360}$ 70. This can be rationalized by considering this sample with the shortest and most flexible chain in Table $1^{30,49}$ and hence, with the lowest capacity to aggregate. Accordingly, $\mathrm{CS}_{360-70}$ not only does not meet the general dependence of $\mathrm{I}_{1} / \mathrm{I}_{3}$ and $\mathrm{I}_{\mathrm{E}} / \mathrm{I}_{\mathrm{M}}$ with $\mathrm{DP}$ 70 (Figure 3), but also displays an excimer at $470 \mathrm{~nm}$ typical of pyrene in solution (Figure 2). ${ }^{50}$
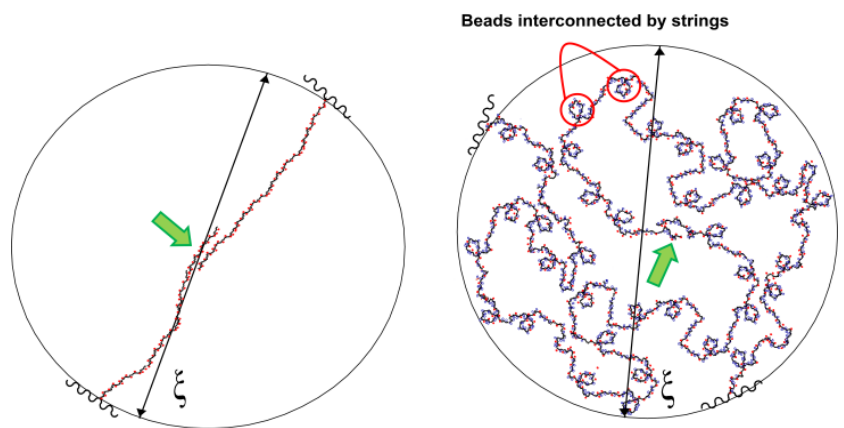

Fig. 5. Schematic representation of end to end aggregation (green arrow) between CS chains of low (left) and high (right) DA. Charges are 75 represented by red points and acetyl groups by blue points.

Rheology. The viscosity of CS solutions has been reported to decrease on increasing DA up to intermediate DA values, and to increase afterwards. ${ }^{51,52,53}$ This higher ability to aggregate of the 80 more acetylated CS contradicts our observations by pyrene fluorescence and has been interpreted as hydrophobic interactions by the $N$-acetyl groups. Table 2 shows the shear viscosity of CS with representative DP and DA values $\left(\mathrm{CS}_{360-1}, \mathrm{CS}_{360-39}, \mathrm{CS}_{360-70}\right.$, $\mathrm{CS}_{1200-3}, \mathrm{CS}_{1200-50}, \mathrm{CS}_{1200-70}$ ) at a concentration of $8 \mathrm{~g} / \mathrm{L}$ in 0.056 ${ }_{85} \mathrm{M}$ TFA. While $\mathrm{CS}_{1200}$ displays the highest viscosity at DA 70, $\mathrm{CS}_{360}$ shows decreasing viscosity values on increasing DA in the whole range 1-70. In accordance to these results, all samples analysed show a Newtonian behaviour with the exception of $\mathrm{CS}_{1200-70}$, where a pseudo-plastic effect (typical of polymer 90 solutions with strong intermolecular interactions) is observed (Figure 6). 
Table 2. Shear Viscosity of CS at $100 \mathrm{~s}^{-1}(8 \mathrm{~g} / \mathrm{L}, 0.056 \mathrm{M}$ TFA $)$.

\begin{tabular}{cc}
\hline $\mathrm{CS}$ & Viscosity (mPa.s) \\
\hline $\mathrm{CS}_{360-1}$ & 4.76 \\
$\mathrm{CS}_{360-39}$ & 4.30 \\
$\mathrm{CS}_{360-70}$ & 2.80 \\
$\mathrm{CS}_{1200-3}$ & $37.3(42.8)^{a}$ \\
$\mathrm{CS}_{1200-50}$ & 28.4 \\
$\mathrm{CS}_{1200-70}$ & $132(16.1)^{a}$ \\
${ }^{a}$ Results obtained with solutions aged for 12 days.
\end{tabular}
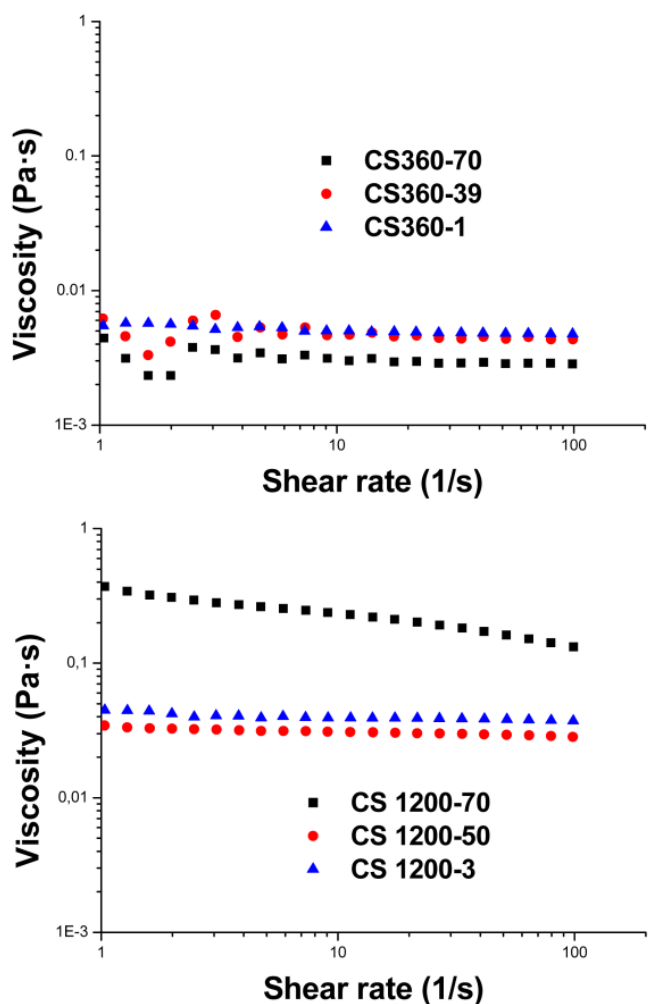

5 Fig.6 Viscosity of CS samples with different DP and DA (8 g/L, 0.056 M TFA).

With the aim of explaining these apparently contradictory results, we turned our attention to aggregates observed by SEC10 MALLS in samples with high DA and DP (Figure S3). These aggregates could be removed by filtration (Figure S4), suggesting the presence of not completely dissolved polymer chains in these samples. Confirmation of this hypothesis came from a rheological study of samples $\mathrm{CS}_{1200-3}$ and $\mathrm{CS}_{1200-70}$ with solutions aged for 12

15 days instead of $24 \mathrm{~h}$ before measurements. No significant difference was observed in the rheological behavior of $\mathrm{CS}_{1200-3}$, but a drastic decrease of viscosity (and disappearance of pseudoplastic effect) was revealed for $\mathrm{CS}_{1200-70}$ in agreement with a continuous decrease of viscosity for CS with DA, independently

20 on DP (Figure 7 and Table 2). This observation was confirmed by measuring the response to the oscillatory shear stress (storage and loss moduli, $G^{\prime}$ and $\left.G^{\prime \prime}\right)$. Thus, $G^{\prime \prime}$ showed a similar dependence on DA and DP than viscosity (Figure S5), and an important decrease of $\mathrm{G}^{\prime \prime}$ was also observed for $\mathrm{CS}_{1200-70}$ after 12 days

25 (Figure S6). Accordingly, G' could be determined for $\mathrm{CS}_{1200-70}$ only after $24 \mathrm{~h}$ of aging, but not after 12 days.

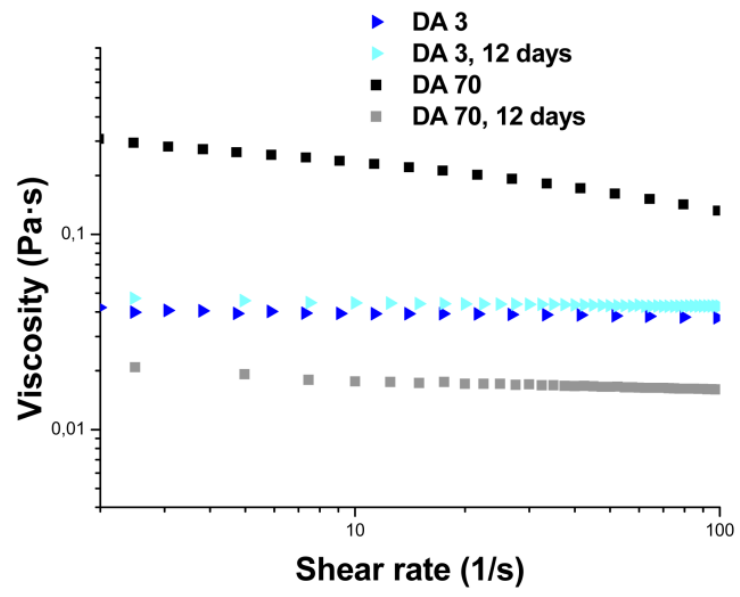

Fig.7 Viscosity evolution in solutions of $\mathrm{CS}_{1200}$ aged for $24 \mathrm{~h}$ and 12 days (8 g/L, 0.056 M TFA).

30 In the light of these results we conclude that samples aged enough to ensure complete polymer dissolution afford a continuous decrease of viscosity with DA independently on DP. It is therefore reasonable to suggest that reports describing a higher tendency to aggregate for the more acetylated CS might 35 derive from not completely dissolved polymer chains rather than hydrophobic interactions between the $N$-acetyl groups.

\section{Conclusions}

The aggregation of CS has been studied as a function of concentration, DA, and DP. Fluorescence experiments point to 40 the presence of HD in the aggregates which are more favored as lower the DA and DP. Consistent with these results, the viscosity of CS solutions decreases continuously with DA in the whole range of DP. These results rule out the participation of the acetyl groups in the formation of HD and have been interpreted by the 45 theory of hydrophobic polyelectrolytes in terms of the lower electrostatic energy of the aggregates. Because of the relevance of aggregation in most bioapplications of CS, these results will be of help for fine-tuning structure-property relationships in novel CS systems.

\section{so Acknowledgements}

This work was financially supported by the Spanish Government (CTQ2009-10963 and CTQ2009-14146-C02-02) and the Xunta de Galicia (10CSA209021PR and CN2011/037). The authors thank Prof Andrey V. Dobrynin (University of Connecticut) for fruitful discussions 55 and the development of Eq. 1. Thanks are also given to Prof. Carmen Alvarez-Lorenzo and Prof. Manuel Mosquera (University of Santiago de Compostela) for help with rheology and fluorescence measurements, respectively.

${ }_{60}$ Electronic Supplementary Information (ESI) available: pyrene fluorescence spectra, SEC-MALLS elugrams, $I_{E} / I_{M}$ and $I_{1} / I_{3}$ ratios in acetate buffer, and $\mathrm{G}^{\prime}$ and $\mathrm{G}^{\prime \prime}$ graphics. 


\section{References}

[1] Ravi Kumar MNV, Muzzarelli, RAA, Muzzarelli, C, Sashiwa, H, Domb, AJ. Chem. Rev. 2004;104:6017-6084.

[2] Amidi M, Mastrobattista, E, Jiskoot, W, Hennink, WE. Adv. Drug Delivery Rev. 2010;62:59-82.

[3] Sarmento B, das Neves J, editors. Chitosan-based systems for biopharmaceuticals: Delivery, targeting and polymer therapeutics. John Wiley \& Sons, Ltd; 2012.

[4] Barbosa JN, Amaral, IF, Águas, AP, Barbosa, MA. J. Biomed. Mater. Res. Part A 2010;93A:20-28.

[5] Hu J, Hou, Y, Park, H, Choi, B, Hou, S, Chung, A, Lee, M. Acta Biomater. 2012;8:1730-1738.

[6] Yi H, Wu, L-Q, Bentley, WE, Ghodssi, R, Rubloff, GW, Culver, JN, Payne, GF. Biomacromolecules 2005;6:2881-2894.

[7] Harish Prashanth KV, Tharanathan, RN. Trends Food Sci. Technol. 2007; 18:117-131.

[8] Rinaudo M. Polym. Int. 2008;57:397-430.

[9] Desbrieres J. Biomacromolecules 2002;3:342-349.

[10] Cho J, Heuzey, M-C, Bégin, A, Carreau, PJ. J. Food Eng. 2006;74:500-515.

[11] Dong Y, Xu, C, Wang, J, Wu, Y, Wang, M, Ruan, Y. J. Appl Polym. Sci. 2002;83:1204-1208.

[12] Chang JS, Chang, KLB, Tsai, ML. J. Appl. Polym. Sci. 2007; 105:2670-2675.

[13] Ottøy MH, Vårum, KM, Christensen, BE, Anthonsen, MW, Smidsrød, O. Carbohydr. Polym. 1996;31:253-261.

[14] Lamarque G, Cretenet, M, Viton, C, Domard, A. Biomacromolecules 2005;6:1380-1388.

[15] Rinaudo M, Milas, M, Dung, PL. Int. J. Biol. Macromol. 1993;15:281-285

[16] Kjøniksen A-L, Iversen, C, Nyström, B, Nakken, T, Palmgren, O. Macromolecules 1998;31:8142-8148.

[17] Buhler E, Rinaudo, M. Macromolecules 2000;33:2098-2106.

[18] Pa J-H, Yu, TL. Macromol. Chem. Phys. 2001;202:985-991.

[19] Korchagina EV, Philippova, OE. Biomacromolecules 2010;11:34573466.

[20] Boucard N, David, L, Rochas, C, Montembault, A, Viton, C, Domard, A. Biomacromolecules 2007;8:1209-1217.

[21] Dobrynin AV, Rubinstein, M, Obukhov, SP. Macromolecules 1996;29:2974-2979.

[22] Dobrynin AV, Rubinstein, M. Macromolecules 1999;32:915-922.

[23] Dobrynin AV, Rubinstein, M. Prog. Polym. Sci. 2005;30:1049-1118.

[24] Amiji MM. Carbohydr. Polym. 1995;26:211-213.

[25] Philippova OE, Volkov, EV, Sitnikova, NL, Khokhlov, AR, Desbrieres, J, Rinaudo, M. Biomacromolecules 2001;2:483-490.

[26] Chen L, Chen, D-H, Wu, C-L. Chinese J. Chem. 2003;21:1224-1228.

[27] Liu WG, Zhang, X, Sun, SJ, Sun, GJ, Yao, KD, Liang, DC, Guo, G, Zhang, JY. Bioconjugate Chem. 2003;14:782-789.

[28] Philippova OE, Korchagina, EV, Volkov, EV, Smirnov, VA Khokhlov, AR, Rinaudo, M. Carbohydr. Polym. 2012;87:687-694.

[29] Ogawa K, Yui, T, Okuyama, K. Int. J. Biol. Macromol. 2004;34:1-8.

[30] Novoa-Carballal R, Fernandez-Megia, E, Riguera, R. Biomacromolecules 2010;11:2079-2086.

[31] Lallana E, Fernandez-Megia, E, Riguera, R. J. Am. Chem. Soc. 2009;131:5748-5750.

[32] Karatas H, Aktas, Y, Gursoy-Ozdemir, Y, Bodur, E, Yemisci, M, Caban, S, Vural, A, Pinarbasli, O, Capan, Y, Fernandez-Megia, E, Novoa-Carballal, R, Riguera, R, Andrieux, K, Couvreur, P, Dalkara T. Journal of Neuroscience 2009;29:13761-13769.

[33] Raviña M, Cubillo, E, Olmeda, D, Novoa-Carballal, R, FernandezMegia, E, Riguera, R, Sánchez, A, Cano, A, Alonso, MJ. Pharm. Res. 2010;27:2544-2555.

[34] Novoa Carballal, R., Ph.D. thesis. University of Santiago de Compostela, 2009.

[35] Fernandez-Megia E, Novoa-Carballal, R, Quiñoá, E, Riguera, R. Carbohydr. Polym. 2005;61:155-161.
[36] Shigemasa Y, Matsuura, H, Sashiwa, H, Saimoto, H. Int. J. Biol. Macromol. 1996;18:237-242.

[37] Vårum KM, Antohonsen, MW, Grasdalen, H, Smidsrød, O. Carbohydr. Res. 1991;211:17-23.

[38] Mima S, Miya, M, Iwamoto, R, Yoshikawa, S. J. Appl. Polym. Sci. 1983;28:1909-1917

[39] Vachoud L, Zydowicz, N, Domard, A. Carbohydr. Res. 1997;302:169-177.

[40] Sorlier P, Viton, C, Domard, A. Biomacromolecules 2002;3:13361342.

[41] Schatz C, Viton, C, Delair, T, Pichot, C, Domard, A. Biomacromolecules 2003;4:641-648.

[42] Schatz C, Pichot, C, Delair, T, Viton, C, Domard, A. Langmuir 2003;19:9896-9903.

[43] Yamazaki I, Tamai, N, Yamazaki, T. J. Phys. Chem. 1987;91:35723577.

[44] Winnik FM. Chem. Rev. 1993;93:587-614.

[45] Ingratta $\mathrm{M}$, Hollinger, J, Duhamel, J. J. Am. Chem. Soc. 2008;130:9420-9428.

[46] Kalyanasundaram K, Thomas, JK. J. Am. Chem. Soc. 1977;99:20392044.

[47] Strand SP, Tommeraas, K, Varum, KM, Ostgaard, K. Biomacromolecules 2001;2:1310-1314.

[48] Sorlier P, Denuzière, A, Viton, C, Domard, A. Biomacromolecules 2001;2:765-772.

[49] Lamarque G, Lucas, J-M, Viton, C, Domard, A. Biomacromolecules 2005;6:131-142.

[50] Van Dyke DA, Pryor, BA, Smith, PG, Topp, MR. J. Chem. Ed. 1998;75:615-620.

[51] Wang W, Xu, D. Int. J. Biol. Macromol. 1994;16:149-152.

[52] Montembault A, Viton, C, Domard, A. Biomacromolecules 2005;6:653-662.

[53] Hu Y, Du, Y, Yang, J, Tang, Y, Li, J, Wang, X. Polymer 2007:48:3098-3106 